\title{
Projects of the Teaching and Popularization section of LIADA
}

\author{
Paulo Sergio Bretones ${ }^{1,2}$ and Vladimir C. de Oliveira ${ }^{2}$ \\ ${ }^{1}$ Instituto Superior de Ciências Aplicadas, Limeira, Brazil \\ email: bretones@mpc.com.br \\ ${ }^{2}$ Instituto de Geociências, Universidade Estadual de Campinas, Campinas, Brazil
}

\begin{abstract}
The goal of this work is to present an analysis of the observational projects developed by the Teaching and Popularization Section of the Liga Ibero-Americana de Astronomía (LIADA). The Section is based in Brazil and counts on the support of 16 volunteer coordinators from most Latin-American countries. The observational projects are described on the home page of LIADA and aim to attract the attention of the general public, teachers and students to encourage their active participation in observational astronomy. The strategy is to circulate support material and open a discussion forum about each of the astronomical phenomena to enhance their consideration by and visibility to the public. Participants' reports are posted on the Internet forum and the web page of LIADA. We have analyzed the records of these activities and present an evaluation of the difficulties with written reports, the need of a dynamic maintenance of the home page, the establishment of a useful communications network and the visibility of the activities of LIADA.
\end{abstract}

Keywords. Astronomy education, astronomy popularization, Latin America

\section{Introduction}

The growing importance of scientific education in the last several decades can be seen in the quotidian presence of technical and scientific principles in modern life. However, there is a defective education in a general way in these matters. The teaching and popularization of astronomy offers many possibilities for astronomers and educators to improve scientific literacy (Percy, 1998a). Many national and international efforts have been made by means of several astronomical institutions in this regard, including, the Brazilian Astronomical Society (Sociedade Astronômica Brasileira) and IAU Commission 46.

The occurrences of astronomical phenomena such as conjunctions, oppositions, eclipses and transits present excellent opportunities to draw the attention of people to the observation of the night sky and more specifically for the teaching and popularization of these phenomena (Bretones and Oliveira, 2004a, 2004b and 2005; Pasachoff, 1998). In this context, amateur astronomers can contribute with actions that promote the teaching and popularization of astronomy in various ways (Percy, 1998b).

The purpose of this study is to present an analysis of the projects developed by the Teaching and Popularization Section (SEDA) of the Ibero-American Astronomy League (LIADA) during the period 2000 to 2005.

\section{The Ibero-American League of Astronomy}

The Ibero-American League of Astronomy (LIADA), was created in 1982, as a reorganization and legacy of the Latin American League of Astronomy (LIADA), founded 
in 1958. Among its objectives, LIADA tries to organize, conduct and facilitate the efforts of amateurs and semi-professionals in Ibero-America and to promote the works of its members. Some professional astronomers enhance the collaboration between the two groups that share our activity. With its current headquarters in Argentina and members spread over many countries, LIADA has sections in several areas of astronomy. LIADA promotes the Internet groups foro-liada and ensenianza-liada, and publishes the electronic bulletin La Red de Observadores (The Network of Observers) and the electronic magazine Universo Digital available on the LIADA website at www.liada.net .

Since 1992 the Teaching and Popularization Section (SEDA) of LIADA has been coordinated in Brazil and since 1998 the Section has had a website on the Internet. That website is hosted by the Morro Azul Observatory of the Instituto Superior de Ciências Aplicadas (ISCA) Faculdades in Limeira at the address www. iscafaculdades.com.br/liada . This is not exactly an educational site but it can be useful for anyone who works in astronomy education. The site shows the activities of the Section, lists local coordinators and their projects, and posts messages and reports of educational activities.

\section{Local coordinators}

Since 2001, 16 Section local coordinators have been appointed in several countries: 2001: Uruguay and Argentina; 2002: Mexico; 2003: Cuba, Guatemala and Panama; 2004: Peru, Paraguay, Chile, Venezuela, Honduras, El Salvador, Costa Rica, Spain; 2005: Colombia, Dominican Republic. The appointment of local coordinators has as its objective the decentralization of LIADA activities and promotion of activities in the various regions. Coordinators are nominated mainly as a result of their activities in astronomy education. It is thus expected that they will report on activities and projects developed in their own countries. The website shows the name, photograph, e-mail address, country and flag for each coordinator. It also lists the annual projects and reports since their appointment.

\section{Projects}

The present paper analyses the various observational projects (e.g. oppositions, conjunctions, eclipses and transits) that aim to attract the attention of the general public, students and teachers to encourage their participation in observational activities.

As an example for further analysis, we discuss projects related to eclipses. A particular eclipse event will have a page listing an observing project, articles and pedagogical material on eclipses, a discussion forum and links to related sites.

To initiate an observing project, the coordinator sends a general email message and posts an article which typically covers some of the following points:

- It remarks that an astronomical phenomenon, such as an eclipse, is a great opportunity for people to observe the sky;

- It invites those knowledgeable to write articles, give interviews to newspapers, radio and television, give lectures, exhibitions and observation sessions;

- It requests further, more specific articles with information about the phenomenon;

- It mentions that the starting article is just an example of the expected follow-up material;

- It invites people interested in the teaching and popularization astronomy to use the space of LIADA Forum to report their projects;

- It requests reports of the results of those projects. In some cases of specially useful information, these reports of activities are included in our teaching and popularization reports; 
Table 1. Messages and reports sent by countries for the Lunar Eclipse of 8-9 November 2003.

\begin{tabular}{lrlr}
\hline Messages & \multicolumn{3}{l}{ Reports } \\
\hline Guatemala & 15 & Argentina & 5 \\
Argentina & 10 & Guatemala & 3 \\
Argentina & 10 & Brazil & 1 \\
Mexico & 1 & Mexico & 1 \\
Spain & 1 & Uruguay & 1 \\
\hline Total & 37 & Total & 11 \\
\hline
\end{tabular}

Table 2. Messages and reports of phenomena covered by LIADA members.

\begin{tabular}{lccccc}
\hline Phenomenon & Date & Messages & Countries & Reports & Countries \\
\hline Eclipse & $15-16 / 05 / 03$ & 14 & 4 & 19 & 7 \\
Mars Opposition & $27 / 08 / 03$ & 21 & 8 & 14 & 6 \\
Eclipse & $8-9 / 11 / 03$ & 30 & 5 & 11 & 6 \\
Eclipse & $04 / 05 / 04$ & 4 & 4 & 2 & 2 \\
Transit & $08 / 06 / 04$ & 4 & 3 & 6 & 4 \\
Eclipse & $27 / 10 / 04$ & 52 & 9 & 26 & 8 \\
Eclipse & $08 / 04 / 05$ & 22 & 9 & 8 & 7 \\
\hline
\end{tabular}

- It mentions that we are interested in stimulating initiatives of this kind and consider them as LIADA projects, and that we would like measure the outreach of our initiatives.

Since the beginning of 2004 projects launched in the forum have also had a Spanish version prepared by the Secretary of LIADA, Jorge Coghlan. For each phenomenon, the relevant messages and reports for educational purposes are selected by the coordinator and posted in the Section page. All this information is properly acknowledged and linked in the page.

Following the example of the eclipse of November 2003, an account of the messages and reports by countries was performed as shown in Table 1. Table 2 shows a list of events covered by LIADA members, excepting those related to conjunctions.

\section{Discussion}

In a preliminary analysis of our study period, we could verify that the space created by the LIADA web page contributed to improved organization of the information and reports on educational activities. However, the expected increase of posted messages due to the efforts of the Section was not observed.

In a general way, the reports are generally provided by the local coordinators of several countries and by active individuals that seize the opportunities as they arise. There are other members who show their ongoing activities and interest from time to time. The absence of representatives of national institutions is noticeable. There were many reports received from Argentina, which may be related to the presence of LIADA's headquarters in that country since 2000. There was also the shortage of institutions and people contributing from Brazil; a much larger number had been expected.

One problem with the posted reports was an over-emphasis on the description of instruments used in the observations, with specific details such as the aperture, eyepieces, local circumstances of the phenomenon and details or personal descriptions of the activity realized, while little or no information was provided regarding the number of people that participated, the programming of the activity, whether it was done for students, which 
school grade they were, in which school it was, teachers, subjects involved, etc. Such reports were not considered useful for the collection of educational data. The reasons for this are: a) The forum receives every kind of report; b) The sender of the reports is not particularly concerned with educational purposes; c) Lack of training in the area of education is not just a feature of the amateurs and institutions, but is it also the case for researchers whose main subject is not education. However, in many cases the encouragement of isolated amateurs and institutions by the Section was clearly verified and resulted in an improvement of the educational contents of these reports.

A principal result of this project is to give visibility to the well developed projects in various countries by institutions and individuals in those countries. The reports also constitute a useful data set for further analyses, for reflections and exchange of experiences, and for the establishment of a network for future projects.

The reports also shed light on the performance of local coordinators and their approach. For many of them, the reports still refer to personal experiences and are not necessarily representative of their whole countries. However, some of the reports show significant levels of activity given the astronomical development of their countries

\section{Conclusion}

An evaluation of the Teaching and Popularization Section activities was performed. The main positive result is that a forum for reports about astronomy education was established. However, there are still operational difficulties to maintain the page on the Internet because of a lack of staff. The question of language - translation of the projects from Portuguese into Spanish and back - if judged from the projects that have already been translated, has been practically solved.

It would be opportune to promote activities more frequently, whenever phenomena occur, such as conjunctions of the Moon with planets and bright stars, meteor showers, etc. We suggest that it would be interesting to analyze other relevant aspects with the reports available on the page. Additional work is needed to improve the information about educational methodologies relevant for the preparation of the activities and reports for the use of interested amateurs, teachers and researchers. A report guide sheet could be prepared. Finally, it would be useful to maintain continuity with local coordinators while bringing in additional countries to expand the LIADA work space, which would make an important contribution to astronomy education in the region.

\section{References}

Bretones, P.S. \& de Oliveira, V.C. 2004a, In: S. Musso (ed.) Primer Congreso de Astronomía del Centro de Estudios Astronómicos de Mar del Plata, Centro de Estudos Astronómicos de Mar del Plata, 5 pp.

Bretones, P.S. \& de Oliveira, V.C. 2004b, Universo Digital, vol. 53, p. 115. See also http://www.liada.net/universo/digital/Morro\%20Azul/Conferencia\%20Vladimir/ Artigo $\% 2018 \%$

Bretones, P.S. \& de Oliveira, V.C. 2005, Boletim da Sociedade Astronômica Brasileira, vol. 25, n. 1 , p. 16

Percy, J.R. 1998a, In: L. Gouguenheim, D. McNally and J.R. Percy (eds.), IAU Colloquium 162 - New Trends in Astronomy Teaching, , Cambridge University Press, p. 2.

Percy, J.R. 1998b. In: L. Gouguenheim, D. McNally and J.R. Percy (eds.), IAU Colloquium 162 - New Trends in Astronomy Teaching, , Cambridge University Press, p. 205

Pasachoff, J.M. In: L. Gouguenheim, D. McNally and J.R. Percy (eds.), IAU Colloquium 162 New Trends in Astronomy Teaching, , Cambridge University Press, p. 202 